\title{
Quantification of Dental Occlusal Variation: A Review of Methods
}

\author{
Edward F. Harris ${ }^{1 *}$ and Robert S. Corruccini² \\ ${ }^{1}$ Department of Orthodontics, University of Tennessee, Memphis, Tennessee \\ ${ }^{2}$ Department of Anthropology, Southern Illinois University, Carbondale, Illinois
}

\begin{abstract}
Occlusion-how the teeth fit together within and between the arches - has important consequences functionally and especially esthetically. Occlusal variation is considerable in modern westernized societies, but the occurrence and extent of the variation appear to be lower in the past and lower in non-westernized groups. This methodological paper describes several commonly-used variables that, collectively,
\end{abstract}

Dental "occlusion" refers to how well the teeth are arranged individually and one-to-another within and between the dental arches. Grainger (1967) suggests that, "malocclusion is any disharmonious variation from the accepted or theoretical normal arrangements of the teeth. But, in nature some degree of variation among individuals of a species is always present."

Proper (ideal) occlusion provides several benefits over maloccluded teeth. Perhaps foremost in contemporary western society, proper occlusion carries an esthetic benefit. People with good occlusion are rated as more attractive, more intelligent, and more desirable employees and spouses than people with malocclusions (Shaw et al., 1979; Shaw, 1981; Shaw et al., 1985; Birkeland et al., 2000; Cerny, 2005; Traebert and Peres, 2007). Proper occlusion involves more tooth-to-tooth contacts, which produces more complete trituration of food (Owens et al., 2002). It is easier to maintain oral health around properly aligned teeth, so health of the periodontium tends to be better and tooth decay may be lessened (e.g., Sergio and Hawley, 1999; Kao et al., 2000; Klages et al., 2007). Above all, a toothy smile is highly sought after in the modern Western world. Morrey and Nelsen (1972:190-198) depict orthodontic interventions. Good articulation and phonation should also be mentioned here, since making certain sounds depends on correct tongue-to-tooth relationships (e.g., Van Norman, 1997; Mohlin and Kurol, 2003). There has been discussion, for example, about the origin of the consonant " $\mathrm{f}$ " and how agriculturally (hence, recently) it arose due to maxillary incisor overjet (Corruccini 1987).

"Malocclusion" is a common term, but it has a couple of shortcomings. There is no clear demarcation between characterize occlusal variation. Methods are described from the literature that measure the location and extent of tooth relations in all three planes of space. Our goal is that, by describing methods in a single source, it will pique the interest of dental researchers to collect these data, so that the space-time distributions of occlusal variations can be known in more detail. Dental Anthropology 2008;21(1):1-11.

a good or adequate occlusion and malocclusion; any distinction is one of degree rather than kind. More importantly, virtually everyone has some sort of "malocclusion," so it is misleading to talk about normal or proper occlusion when we actually mean idealized, perfect occlusion. "Occlusal variation" is a more appropriate, neutral term to refer to the positional variations of teeth and tooth relationships that are found in most people in the absence of orthodontic treatment. Lombardi and Bailit (1972:283) offer a moreinvolved description:

The term "malocclusion," encompassing all deviations of the teeth and jaws from normal alignment, includes a number of distinct conditions which may or may not be independent: malpositioning of individual teeth (rotation, tipping, over- and undereruption); discrepancies between tooth and jaw size (crowding and spacing); and malrelations of the dental arches (sagittal, transverse and vertical). Dental arch malrelations may reflect abnormalities in the dentition, the jaws, or both.

A fundamental dichotomy can be drawn as to the sources of malocclusion, and these two sources can be labeled bone-based and tooth-based (e.g., Harris and Johnson, 1991; Harris, 2008). That is, one way of developing improper occlusion is for the supporting bones of the two jaws to grow "inappropriately." If, for example, the mandible grows forward much more

Correspondence to: Edward Harris, Department of Orthodontics, 870 Union Avenue, University of Tennessee, Memphis, Tennessee 38163.

E-mail: eharris@utmem.edu 
than the maxilla, the teeth supported by these bony elements will not properly interdigitate. Comparably, if the palatal plane of the midface is canted up in the front, the anterior teeth cannot couple between the jaws resulting in an anterior openbite. Bone-based malrelationships can occur in any combination of the three planes of space (e.g., Moyers, 1988; Proffit, 2007), and, given the familial resemblances in the sizes and shapes of the facial bones (e.g., Nakata et al., 1974a,b; Harris, 1975), these "bone-based" causes of malocclusion tend to be under genetic control. Distinct from this are the familiar "crooked teeth," where it is the actual positions of teeth in the alveolar bone that create esthetic and functional problems. These "tooth-based" issues involve the locations, rotations, and angulations of teeth unto themselves as well as one to another. These tooth-based variables appear to be under little genetic control and, conversely, seem to be a consequence of the environment (Corruccini and Potter, 1980; Harris and Smith, 1980).

This dichotomy between bone- and tooth-based causes of malocclusion is not absolute; problems with the sizes of the supporting jaws can preclude proper interdigitation of the teeth-leading to tooth-based occlusal issues. Still, we contend that much of the conflict in the literature about the etiology of malocclusion stems from uncritical lumping of bone- and tooth-based kinds of malocclusion.

The present paper focuses primarily on recording these latter, tooth-based sorts of malocclusion, and these are variables readily measured from inspection of the dental arches (or dental casts) themselves rather than the skeletodental facial complexes (e.g., Athanasiou, 1995).

The purpose of the present paper is to describe some of the methods used by orthodontists and epidemiologists to quantify the extent of a person's occlusal variation. These dimensions are chosen because they can be made with sliding calipers (or a ruler) rather than more complex instrumentation, so the data are at least interval scale (Ellis, 1966) but are fairly simple to collect. Several dimensions can be measured in vivo, but it is much easier on the subject and more consistent and accurate to collect the data from skulls or full-mouth dental casts. The variables can be compounded into a variety of indices expressing overall deviation from the ideal; Kelly and Harvey (1977:Appendix I) present particularly useful details for scoring the "Treatment Priority Index." Our intent is that, by describing these variables, more dental researchers will collect data on malocclusion, providing a richer store of information about the advent, extent, and sorts of malocclusion through human history.

\section{Centric Relation and Centric Occlusion}

Dentists recognize two dental relationships, termed centric relation (CR) and centric occlusion (CO). CR is a stable, reproducible position, where the condyles are seated in their superior-most and rear-most positions in the glenoid fossae (Ramfjord and Ash, 1971). There are, however, mixed views concerning the "best" condylefossa relationship for CR (e.g., Davies et al., 2001). The concept of CR is founded in prosthodontic aspects of dentistry, notably when the patient is edentulous and the dentist requires a reproducible reference position for building a denture. CR also is encountered in research by gnathologists, where the focus often is on rehabilitating a person's dentition to relieve bruxism, temporomandibular dysfunctions, myofacial pain, or other problems. CR can only be determined in living persons; it cannot be determined from dental casts or with skeletal material (because the meniscus and cartilaginous joint linings are absent).

Centric occlusion (CO), in contrast, is a person's habitual bite, and this is the same as maximum intercuspation. CO can generally be determined from casts alone, though the casts may fit together in various ways if the occlusion is particularly poor.

It is of little consequence when measuring occlusal variation, but $\mathrm{CR}$ and $\mathrm{CO}$ often do not coincide. There often is a "slide" from CR forward to CO, but details are beyond this overview (Ramfjord and Ash, 1971). The convention throughout the present review is to place the teeth (or casts) in maximum interdigitation or, synonymously, habitual bite.

\section{Incisor Overbite and Overjet}

The incisal edge of the lower central incisor should be quite close to the lingual contour of the upper incisor when the dentition is in maximum intercuspation. This can be measured vertically (overbite) and horizontally (overjet). Incisor overbite is the vertical (craniocaudal, occlusogingival) distance between the incisal edges of the central incisors (Fig. 1A) measured perpendicular to the occlusal plane. The easiest way to measure this (Baume et al., 1973) is (1) to place the casts in maximum intercuspation, (2) use a fine lead pencil to mark where the incisal edge of the upper incisor occludes over the lower incisor, (3) separate the casts, and (4) use the depth gauge of the calipers to measure how far the pencil mark is from the incisal edge of the lower incisor. One convention is to measure either the left or right central incisors with the greater overbite; others (e.g., Smith and Bailit, 1977) measure both sides and record the average. When the incisors do not meet and there is an anterior openbite (also termed negative overbite and apertognathia), the gap between the incisor edges in the two jaws is measured perpendicular to the occlusal plane, and the value is recorded as a negative value.

Overbite will be underestimated if the incisors are incompletely erupted and also if there is occlusal attrition that has worn down the crown heights. Indeed, considerable attrition-as is common with abrasive 

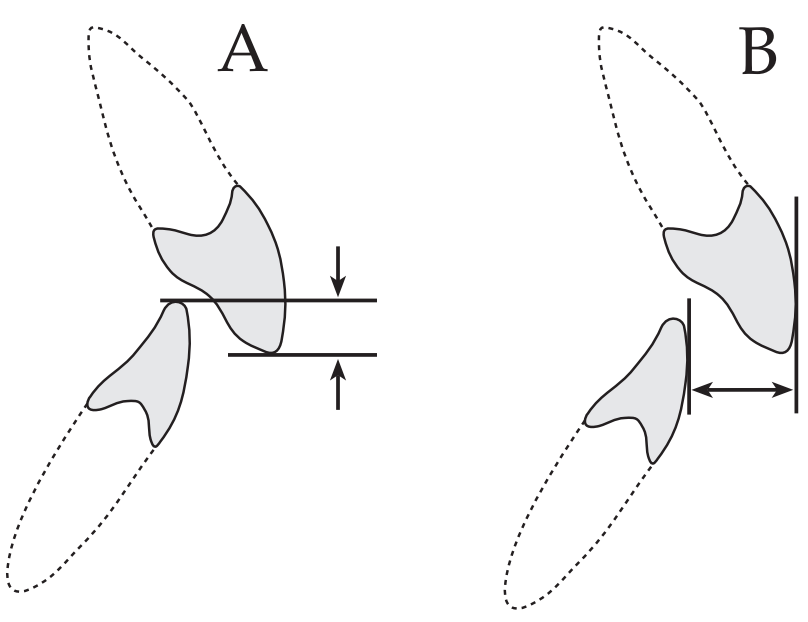

Fig. 1. Lateral view of the central incisors, showing (A) the method of measuring overbite, measured normal to Downs' occlusal plane and (B) overjet measured parallel with Downs' occlusal plane. Incisors with no vertical overlap have a negative overbite (openbite). Incisors in anterior crossbite have a negative value for overjet. Conventionally, the quadrant with the greater deviation is recorded.

diets - will cause the loss of tooth substance to the point that the mandible autorotates into an edge-toedge incisal bite. Brace (1977) argues this edge-to-edge bite is actually the preindustrial norm.

Overjet refers to the horizontal (dorsoventral or labiolingual) distance between the facial tangents of the central incisors in the two arcades (Fig. 1B). With the casts interdigitated, the depth gauge of sliding calipers can be used to measure the distance from the labial surface of the more prominent maxillary central incisor distally to the face of the mandibular antagonist.

If the mandible is very prominent or the maxilla is undersize (or both), the mandibular incisors can be in front of (labial to) the upper incisors (i.e., anterior crossbite). This "underbite" is measured in the same manner as overbite, but the distance is recorded as negative. This occasional situation is variously labeled underjet, negative overjet, reverse overjet, anterior crossbite and mandibular overjet with the last two being most commonly encountered (Grainger, 1967).

\section{Buccal Segment Relationship}

How the molars, particularly the first molar in each arch, fit together in the mesiodistal (parasagittal) plane depends on several factors, including how the teeth are positioned on the supporting basal bone of each arch, but also on the sizes of the upper and lower jaws. "Proper" occlusion occurs when the mesiobuccal cusp of the maxillary first molar is positioned parasagittally in the buccal groove of the mandibular
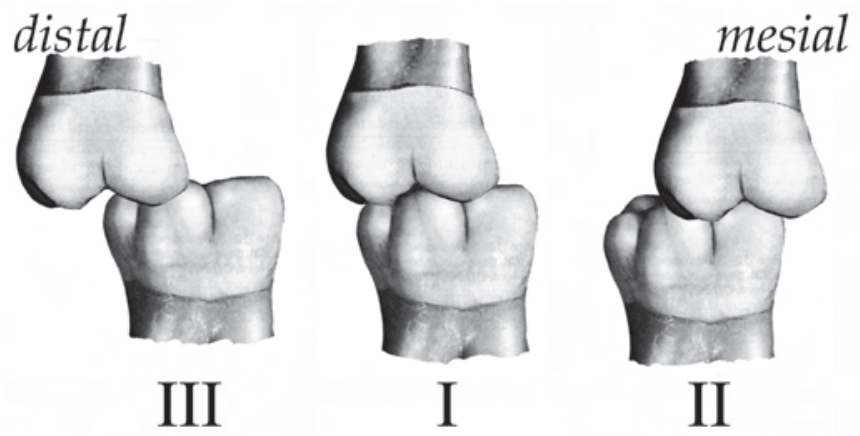

Fig. 2. These buccal views of the permanent first molars depict Edward H. Angle's time-honored three classes of molar relationship. Left: A full-cusp Class III (mesioclusion) relationship occurs when the maxillary tooth is too distal or, more commonly, the mandibular tooth is too mesial. Center: The desired molar relationship (neutroclusion) has the mesiobuccal cusp of the upper molar aligned in the buccal groove of the lower molar. Right: A full-step Class II relationship (distoclusion) is shown, commonly (but not necessarily) due to insufficient horizontal growth of the mandible. It is not necessary to have such extreme (full-cusp) discrepancies to achieve Angle's Class II or III relationships.

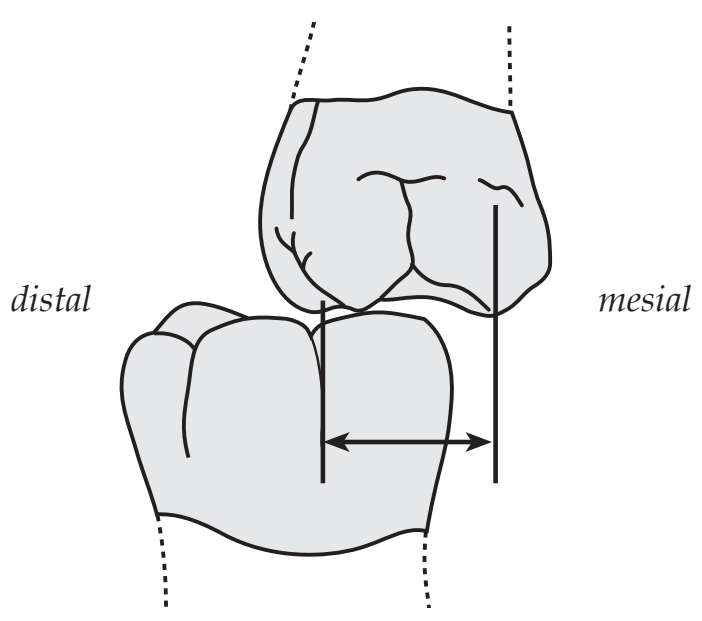

Fig. 3. Buccal segment relationship (BSR) is measured on an interval-scale as the distance (parallel with the occlusal plane) between the mesiobuccal cusp of the upper molar and the buccal groove of the mandibular molar. By convention, the distance is positive in cases of mesioclusion (Class III), negative with distoclusion (Class II), and zero with neutroclusion (Class I). An example of distoclusion is illustrated. 


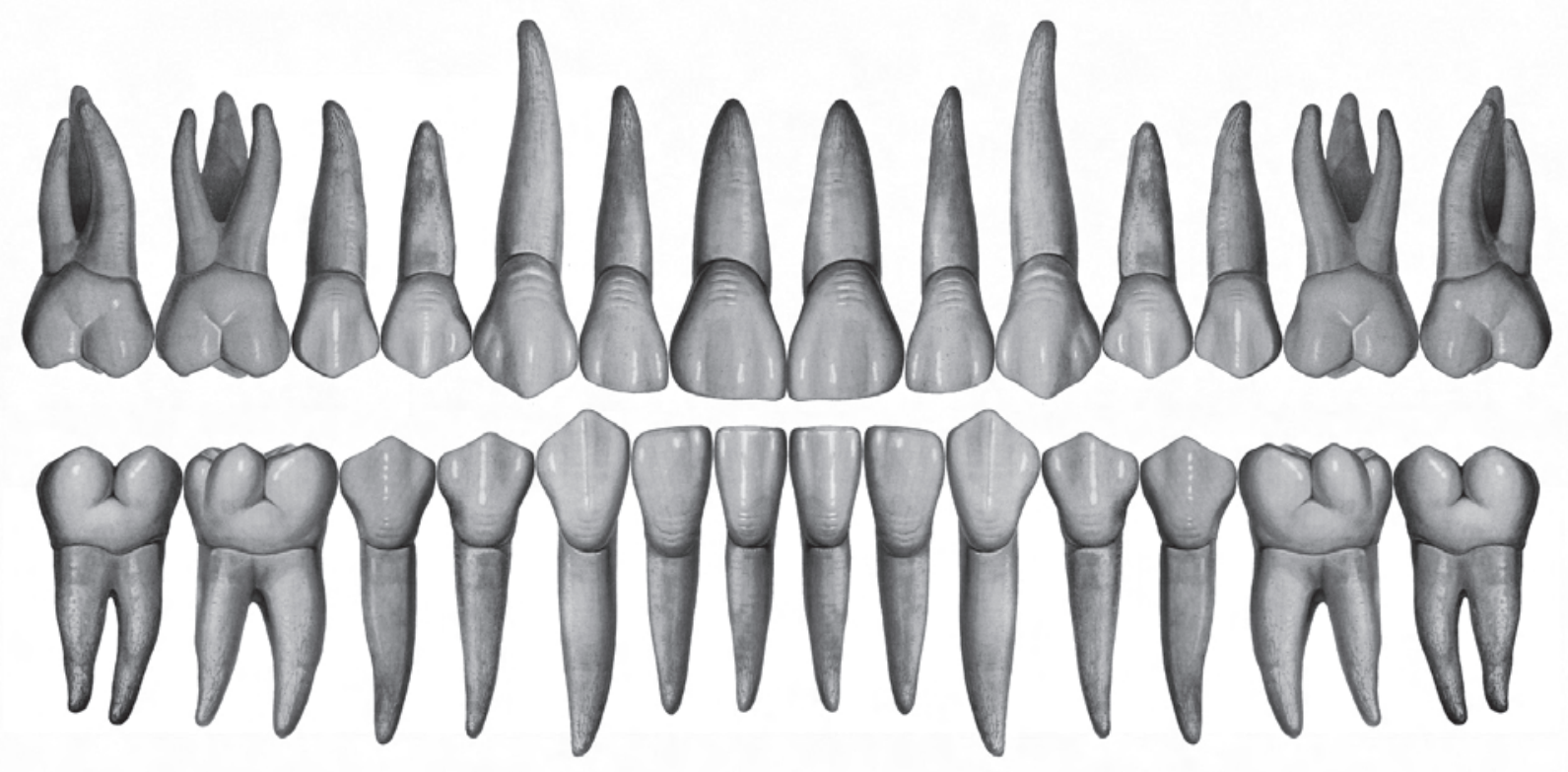

Fig. 4. The mesiodistal crown dimensions of all of these teeth are drawn to the same scale, showing that when a Class I BSR occurs at the first molars, there is a better chance that all of the teeth will be properly aligned within each arch and properly interdigitate between the arches.

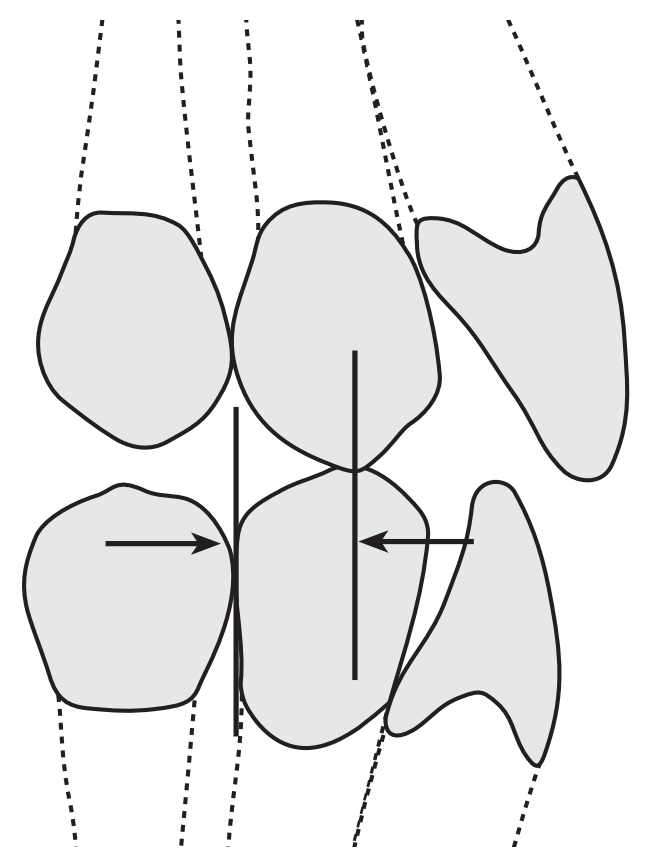

Fig. 5. Lateral view of the canines, showing the method of measuring canine discrepancy, which is the horizontal deviation of the maxillary canine's cusp tip relative to the mandibular canine-first premolar embrasure. The horizontal discrepancy is measured with sliding calipers. If, as diagrammed here, the mandibular canine-premolar embrasure is distal of its ideal position (Class II), the distance is labeled negative. first molar. This is the Angle Class I relation commonly evaluated by orthodontists (Fig. 2). This classification was developed by Edward H. Angle, a historically prominent orthodontist in the late 18th century (e.g., Angle, 1899). Consequently, no "angle" is involved in this categorization of molar relationships. Angle's molar classification can be described more accurately using a continuous scheme that is termed buccal

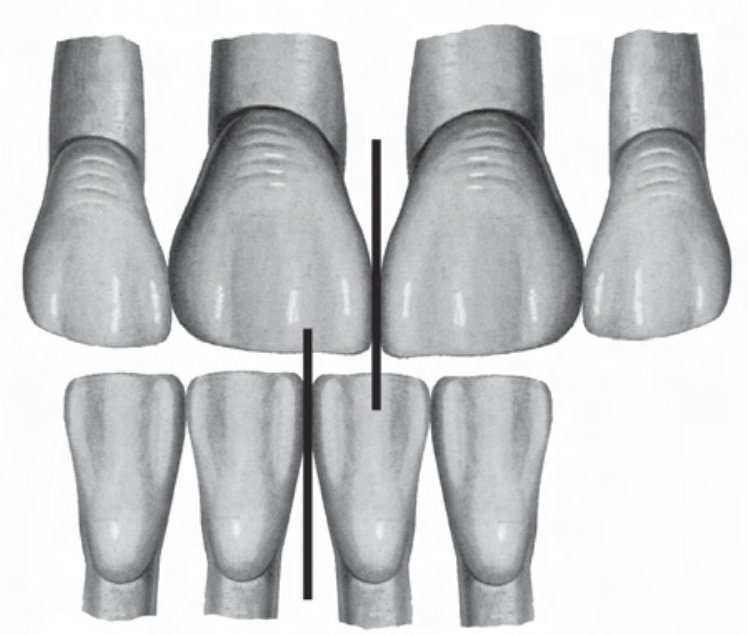

Fig. 6. Diagram of the labial view of the incisors, showing the method of measuring the deviation of the maxillary and mandibular dental midlines. If the midlines are coincident, the discrepancy is zero. The horizontal discrepancy can be measured with sliding calipers. Mandibular shifts to the right are labeled positive (Harris and Bodford, 2007). 


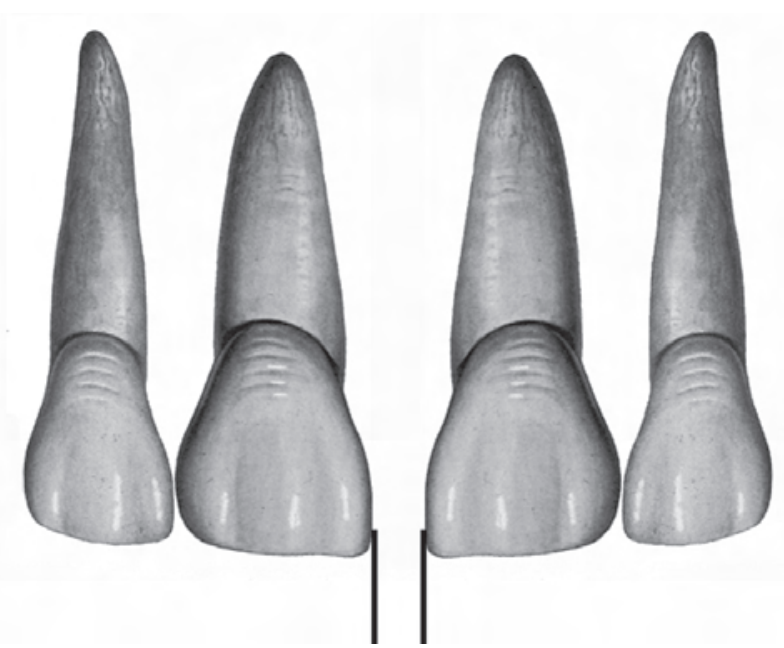

Fig. 7. A diastema occasionally occurs between the maxillary central incisors, often due to a fibrous band of gingival tissue that keeps the teeth apart. Width of the diastema is measured, as shown, between the medial anatomic contact points of the central incisors parallel with the occlusal plane.

segment relationship (BSR; Fig. 3).

Given characteristic mesiodistal crown size relationships for a person's teeth, a Class I molar relationship goes far towards assuring that all of the teeth mesial to the permanent first molars will interdigitate properly between the two arches (Fig. 4). Angle's three-grade classification is a valuable descriptive method, but recording BSR on a continuous scale (Fig. 3) is more informative for most research efforts. When the mesiobucal cusp (paracone) is "socked into" (symmetrically overlaps) the buccal groove, BSR is zero. This corresponds to ideal occlusion of the protocone in the mandibular antagonist's central occlusal fovea and of the hypoconid in the maxillary antagonist's central occlusal fovea (see Hillson 1996:Chapter 4). The value is negative when the lower molar groove is distal of the upper molar's cusp (distoclusion); the value is positive when the groove is mesial to the upper molar's cusp tip (mesioclusion). Left-right asymmetries are common, so it can be useful to score BSR on both sides of the arch (Siegel, 2002).

In practice, the buccal groove extends fairly far down the molar's crown, so it is identifiable with moderate occlusal attrition. The cusp tip can be extrapolated from the wear facet if the upper molar is not severely worn.

\section{Canine relationship}

Analogous with BSR, the parasagittal position of the cusp tip of the maxillary canine can be measured relative to the canine-first premolar embrasure in
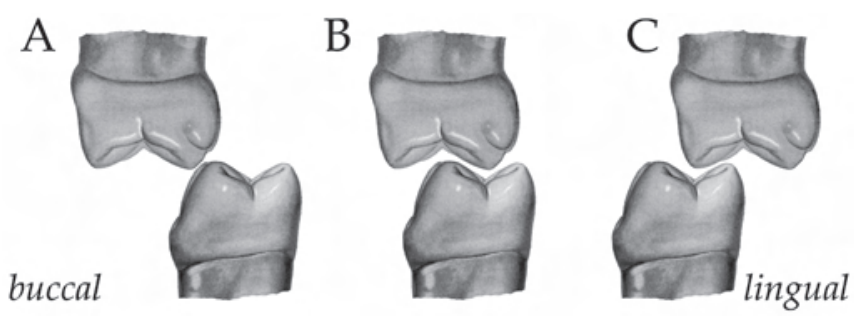

Fig. 8. Facial views of the first molars showing transverse relationships: (A) buccal crossbite; (B) normal mediolateral relationship, with the upper buccal cusp overhanging the mandibular cusp and the upper lingual cusp occluding in the lower molar's central fovea, and (C) lingual crossbite.

the mandible. With ideal interdigitation, the canine's cusp tip should fit into this embrasure (Fig. 5). When the canine is distal of the embrasure, the distance is recorded as negative; otherwise positive (Harris and Bodford, 2007).

\section{Midline deviation}

The dental midlines of the two jaws should be coincident, and, in the living, the dental midline (at the embrasure of the central incisors) also should be coincident with the frenulum in the superior labial vestibule. Midline deviations indicate left-right arch asymmetries. By convention (Harris and Bodford, 2007), when the mandibular dental midline deviates to the right of the maxillary midline, the distance (measured with calipers) is labeled positive; otherwise negative (Fig. 6). When the dental midlines are coincident, the "deviation" is zero.

\section{Midline diastema}

A diastema is a space between teeth, such as occurs between tooth types in many species. In dentistry, a diastema refers specifically to a space or gap between the maxillary central incisors (Fig. 7). A diastemadefined as a space at least $2 \mathrm{~mm}$ wide-was recorded as part of the U.S. National Health Examination Survey (NHANES III; NCHS, 1994). Care has to be taken in contemporary groups that the diastema was not closed orthodontically or restoratively (with, e.g., crowns or composite). The frequency is about $6 \%$ in American whites, but twice that in African Americans (Brunelle et al., 1996).

Figure 7 shows how the width of the diastema is measured millimetrically. It also is important to distinguish between a midline space created by axial deviations of the central incisors that separates these teeth labiolingually versus a true diastema of a mediolateral separation of the incisors' locations in the supporting alveolar bone. Beware also of incisor 


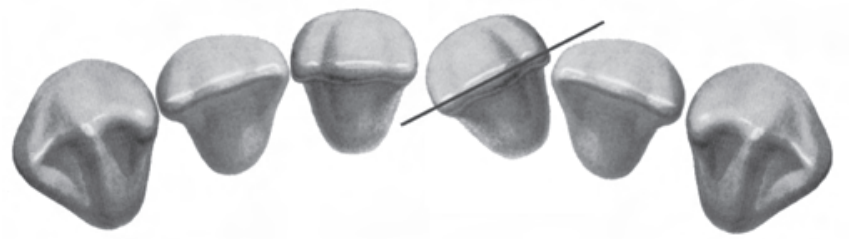

Fig. 9. Tooth rotations are scored as (A) the number of teeth rotated less than $45^{\circ}$ relative to the idealized arch form plus (B) twice the number of teeth rotated $45^{\circ}$ or more. Teeth throughout the dentition are scored. This example shows the rotation of the lower right central incisor of less than $45^{\circ}$ relative to the arch form.

"winging," which may be genetic and unrelated to occlusal variation ( $c f$. Enoki and Dahlberg, 1958). Interdental spacing in the anterior region is much more common in the deciduous dentition, but the larger permanent successors generally use up the space. Some people with a diastema have a fibrous band of gingival tissue that maintains the space.

\section{Posterior Crossbite}

Normally the buccal cusps of the teeth in the maxillary buccal segment (the premolars and molars) should extend laterally and overhang the buccal cusps of the lower "contained" arch (Wheeler, 1965; Ramfjord and Ash, 1971). A posterior buccal crossbite occurs when the maxillary teeth extend too far laterally compared to the mandibular antagonists. Conversely, and more commonly, posterior lingual crossbites occur when the maxillary buccal cusps occlude too lingually.

Several methods of scoring crossbites have been suggested. Baume et al. (1973) propose a simple threegrade ordinal classification of posterior crossbites (Fig. 8). This diagram illustrates full-cusp crossbites (either buccal or lingual), but cases do not have to be this extreme to be counted. Grainger (1967) and Kelly and Harvey (1977) simply count the number of teeth in the premolar-molar arch segments that are buccally or lingually displaced out of the projected arch form, giving special emphasis to deviations of "cusp to cusp" or worse (e.g., paracone apex occludes on the lingual aspect of the protoconid and hypoconid). Smith and Bailit (1977) suggest that the occurrences of lingual and buccal crossbites should be recorded separately.

\section{Tooth Rotations}

A tooth can be located in its ideal position in the dental arch, but rotated around its long axis. The degrees of rotation can be measured (as with a protractor), but most epidemiological studies have opted to use an ordinal scoring scheme (Fig. 9). An unrotated tooth has a rotation score of zero, while rotations can be "minor" or "major." A minor rotation is defined as less that $45^{\circ}$

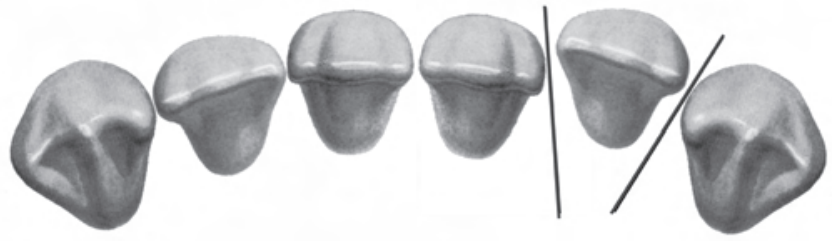

Fig. 10. Tooth displacements are scored as (A) the number of teeth displaced out of the idealized arch form plus (B) twice the number of teeth displaced more than 2 $\mathrm{mm}$ out of the arch form. Teeth throughout the dentition are scored. This example shows a labial displacement of more than $2 \mathrm{~mm}$ of the mandibular lateral incisor.

and is given a score of 1 . A major rotation is $\geq 45^{\circ}$ relative to the arch form and is given a score of 2. Rotation score is the sum for the whole mouth (optionally excluding third molars). In other words, a person's rotation score is the number of teeth with minor rotations plus twice the number of teeth with major rotations (Grainger, 1967; Kelly and Harvey, 1977).

\section{Tooth Displacements}

Teeth can be ectopically positioned out of alignment (Fig. 10). That is, the tooth is effectively in its idealized axial inclination (not tipped) and in its idealized position rotationally, but it is displaced out of the arch form. Van Vark and Pennell (1959) developed an ordinal scale for quantifying tooth displacements. If, visually, a tooth is in its idealized position in the dental arch, its score is zero. If, instead, the tooth is slightly displaced - up to $2 \mathrm{~mm}$-its displacement score is 1 . If the displacement is $>2 \mathrm{~mm}$, its score is 2 . The displacement score for the whole mouth (presumably 28 teeth) is the sum of the scores. Grainger (1967), Kelly and Harvey (1977),

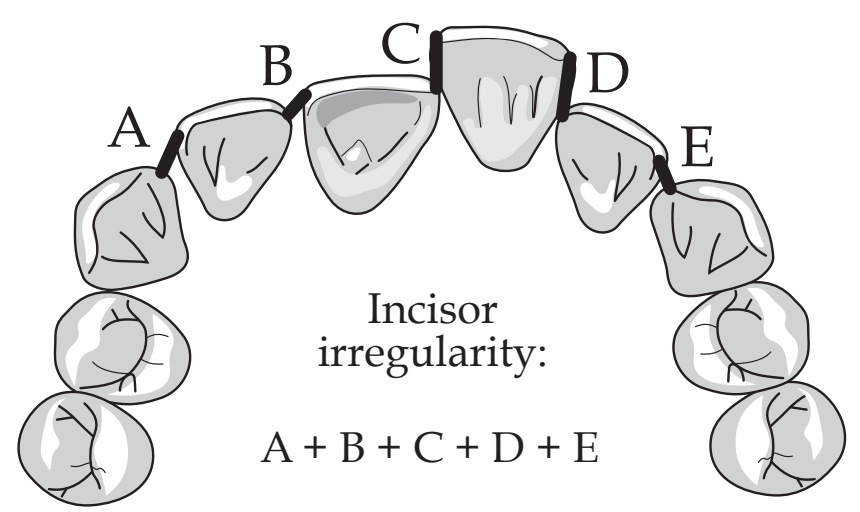

Fig. 11. Incisor irregularity is the millimetric sum of the five anatomic contacts among the six anterior teeth. The maxillary is shown here, though Little (1976) devised the index for measuring crowding in the mandible. When all five contacts are approximated, the index is zero. 
and Smith and Bailit (1977) promote this same scoring method.

\section{Incisor Irregularity}

The most common sort of malocclusion in contemporary westernized populations is incisor crowding (e.g., Brunelle et al., 1996), where there is inadequate supporting arch space for proper alignment of the anterior teeth in one or both arches. Nowadays, the most broadly applied method of quantifying anterior crowding is Little's Incisor Irregularity (Little, 1975). This method was developed for the mandibular arch, but it is equally applicable to the maxillary arcade. As illustrated in Figure 11, there are five interdental contacts between the four incisors plus the adjacent canines in an arcade. In proper occlusion, the anatomic contacts of the adjacent incisors and canines should be closed - so the anatomic contacts of adjacent teeth are together. The greater the dental crowding - reflected as rotations, displacements, and altered axial inclinations of the teeth - the greater the summed distances across the five contacts. The millimetric distances between all open contacts between incisors and canines are measured parallel with the occlusal plane, and the sum is the Incisor Irregularity. Incisor Irregularity can range from zero (when all of the contacts are approximated) to some ill-defined upper limit of "crooked" teeth.

While quite practical, there are at least two shortcomings of Incisor Irregularity. One, the sum is insensitive to "accordioned" teeth, where the teeth themselves are rotated about their long axes, but reciprocally, so the anatomic contacts remain close together. Secondly, Incisor Irregularity is insensitive to interdental spacing. In our experience (e.g., Turner, 2007), it is best to score cases exhibiting interdental spacing-where the open contacts are due to excess arch space for the given tooth widths - as a separate category of malocclusion.

Epidemiological studies (e.g., Grainger, 1967; Baume et al., 1973; Jenny and Cons, 1996) suggest scoring (measuring) just the most deviant tooth, but their emphasis is on facial esthetics and on abbreviating data collection. In our experience, using just the extreme deviation as a proxy for irregularity throughout the anterior segments is coarse and precludes much analysis (Harris et al., 1987). Experience suggests that Incisor Irregularity is a much more comprehensive measure of dental irregularity.

\section{Arch Depth}

Arch depth (e.g., Harris, 1997) is the mesiodistal distance from the labial surface of the central incisors back to the distal margins of the first molar (Fig. 12) along the midline. The anatomic midline of the palate is evident as the midline raphe in the maxilla (or the intermaxillary suture in skeletal material). The midline

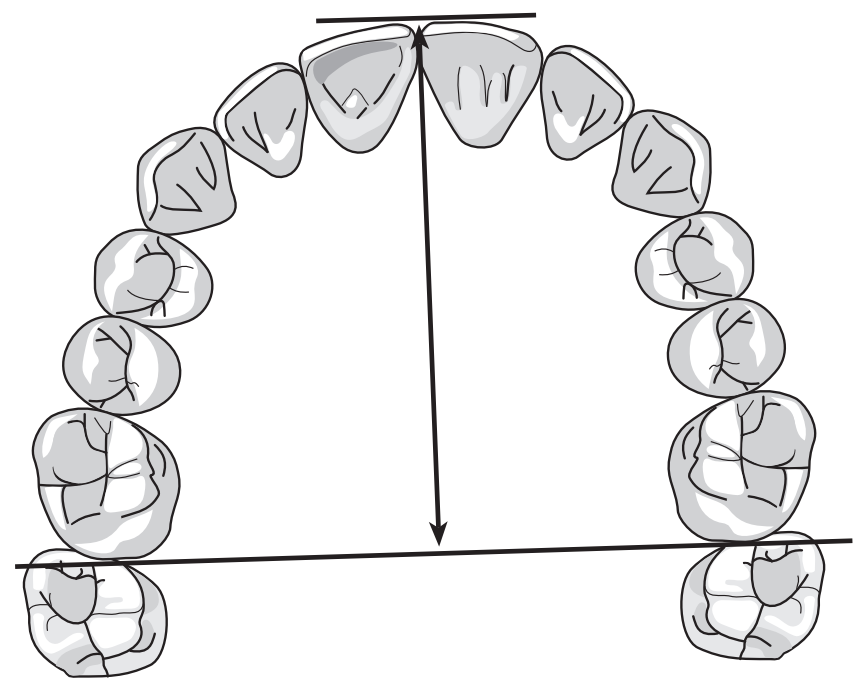

Fig. 12. Diagrammatic illustration of maxillary arch depth. Depth can be measured independently on the maxillary and mandibular arches. Operationally, a straight-edge is positioned against the distal heels of the permanent first molars (so there may be some dentoalveolar asymmetry) and the depth is measured from the labial of the central incisors, along the median raphe, to the back of the first molars.

needs to be estimated in the mandible. Various authors (e.g., Mills, 1964) label this dimension arch length.

Knott (1961), DeKock (1972), and others have employed geometry to determine arch depth as the formula for the median of a triangle with known sides. Using the dental landmarks of A, B, and C in Figure 13, arch depth $\mathrm{D}$ is calculated from the formula

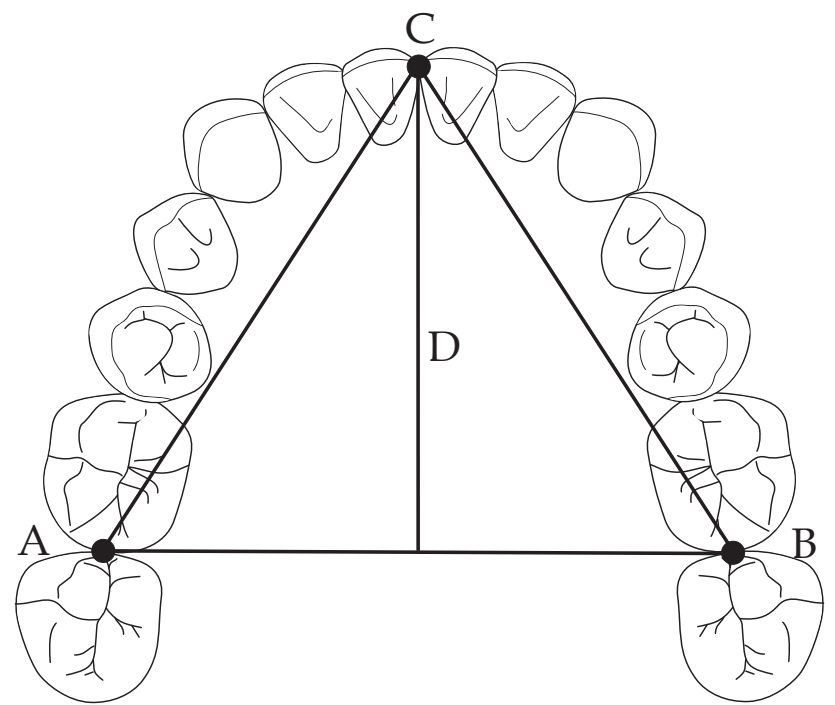

Fig. 13. Once the arch chords $A C$ and $B C$ and arch width $\mathrm{AB}$ are known, arch depth (D) can be calculated as the median height of the triangle (see text). 


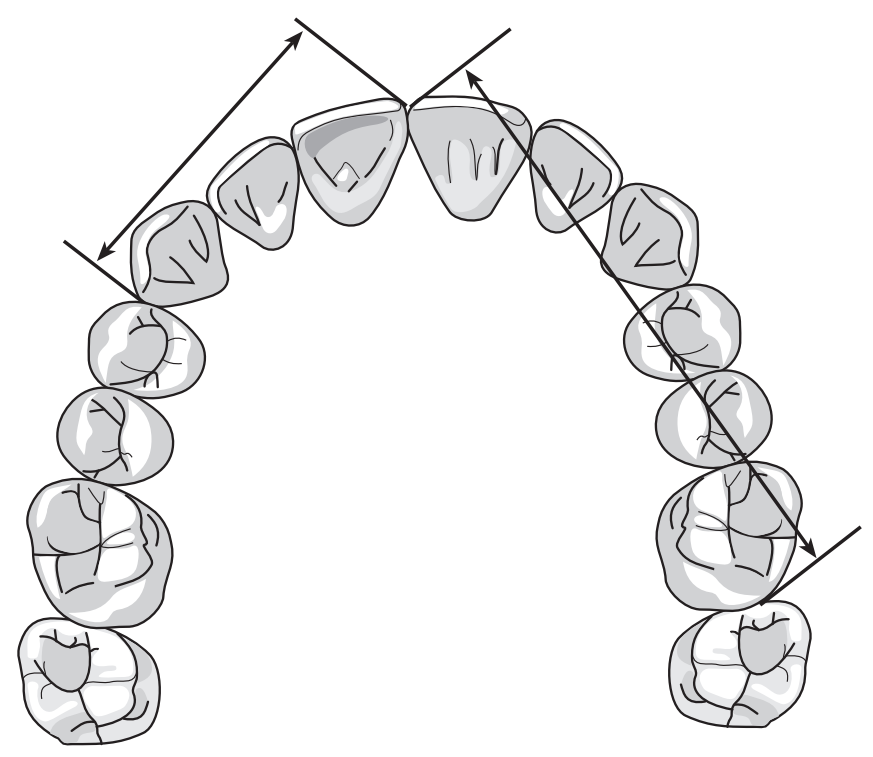

Fig. 14. Diagrammatic illustration of a maxillary dental arch, showing the manner that, with sliding calipers, the incisor-to-canine (1-3) and the incisor-tomolar (1-6) arch chords are measured. In practice, both of these chords can be measured on the left and right sides of both the maxillary and mandibular arches.

$$
\mathrm{D}=\sqrt{\frac{A C^{2}+B C^{2}}{2}-\frac{A B^{2}}{4}}
$$

\section{Arch Chords}

Measures of arch chords (Moorrees and Reed, 1954; Sillman, 1964; Knott, 1972) are included here because their measurement in each quadrant can disclose arch asymmetries. Cassidy et al. (1988) suggested two chord

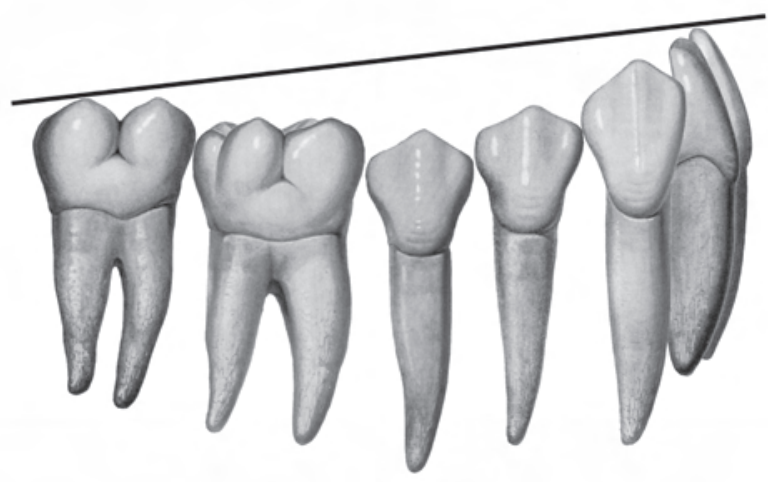

Fig. 15. The curve of Spee is measured as the maximum distance from a plane defined by the most occlusal anterior and posterior teeth. As diagrammed here, this would be in the region of the second premolar. dimensions, one that they labeled a 1-3 chord. This is from the midline embrasure of the central incisors obliquely to the distal heel of the canine (Fig. 14). This would be measured in the corresponding left and right quadrants, and the greater the difference, the greater the bilateral asymmetry. The second chord, labeled the 1-6 chord, is from the same midline embrasure of the central incisors obliquely back to the distobuccal heel of the first molar (Fig. 14). Likewise, this can be done in both quadrants of both arches.

\section{Curve of Spee}

The curve of Spee is the curve defined by the occlusal surfaces of the mandibular teeth in the occlusogingival plane. This eponym refers to Ferdinand Graf von Spee who described the curve as a segment of a circle. Strictly, Spee's curve extends between the canine and the terminal molar. However, the incisors often are included in the measurement (e.g., Bernstein et al., 2007).

The maximum depth of the curve is measured (Fig. 15). A flat object, like a ruler, is laid on the mandibular occlusal surfaces, and the depth of the tooth farthest from this plane-commonly a premolar-is recorded. Oftentimes the incisors are super-erupted, so a greater distance (depth of the curve) is obtained than when excluding the incisors. A shallow curve of Spee is thought to be an integral part of a sound occlusion. The curve deepens as teeth slip their anatomic contacts occlusogingivally.

\section{DISCUSSION}

Any number of anatomical, muscular, behavioral, physiological and other factors can divert one or more teeth out of their "proper" occlusal positions. These factors can be in force as the tooth forms in its crypt, during eruption, and/or after occlusion has been established. The topics of how and why malocclusion develops (and progresses with age) are too complex to be dealt with here (e.g., Proffit, 1985; Harris, 1997; Corruccini, 1999). Instead, our intent is to review some of the common methods used to quantify the nature and extent of occlusal variation.

Deviations of tooth positions from the ideal are far more the rule than the exception among current westernized populations. National surveys of U.S. youths suggest that only about 1 teenager in 10 develops naturally-occurring good occlusion, and fully a third of youths develop malocclusions labeled "severe" and "handicapping" (Kelly and Harvey, 1977; Brunelle et al., 1996). Consequently, "proper" or idealized occlusion is much less common in the absence of treatment than "normal" or average occlusion. Hillson (2005:281-284) argues that occlusal variation is also much higher in domestic than in wild nonhuman animals. With human malocclusions being so common (and probably 
continuing to rise), it is a valuable research question to ask what sorts of malocclusions occur and their severity. Clinically, quantification of the kind and severity of malocclusion is driven by (1) the need to best allocate public funds for treatment of financially disadvantaged citizens, but also (2) to evaluate the difficulty and prognosis of treatment. These efforts are different from the interests of basic scientists who aim to assess the impact of malocclusion on societies, and its population variation through time and space (e.g., Corruccini, 1984; Brunelle et al., 1996).

As we mentioned, the impetus for delineating these measures of occlusal variation is to stimulate interest among dental researchers concerning how these dimensions vary in their own data. It is worth commenting in this vein that several dental considerations can deflect the development of "proper" occlusion. Some developmental considerations, such as eruptive pathways (e.g., Barberia-Leache et al., 2005), patterns of eruption (e.g., Tompkins, 1996), and premature loss of primary teeth (e.g., Fanning, 1962) are difficult or impossible to reconstruct from subjects evaluated in the full dentition, but other developmental factors are more persistent. Data may need to be categorized by age grade, and the variables described here are generally specific to the permanent dentition rather than the mixed dentition because of ongoing changes as the permanent teeth erupt (e.g., Baume, 1950; Moorrees, 1959). For archeological remains (where age at death has to be estimated), the degree of occlusal wear can be a useful proxy (e.g., Smith, 1984) since wear affects occlusal relationships. Also, it generally is useful also to collect data on other, abnormal dental conditions that can affect occlusion, notably (1) congenitally absent teeth, (2) supernumerary teeth, (3) abnormal crown size and form (e.g., macrodontia, microdontia), (4) impacted teeth (and retained primary teeth), and (5) transposed teeth (Baume et al., 1973). Particularly with older subjects, issues of tooth loss due to caries, trauma, and/or periodontal involvement also may impact the occlusal findings because of the life-long effects of the anterior component of force (Southard et al., 1989) and the tension of trans-septal fibers (Picton and Moss, 1973) that shift teeth in areas of interproximal attrition and tooth loss.

Little is known about the effects of occlusal and interproximal attrition on occlusal variation, but abrasion doubtlessly affects the occlusion of adults living with a lot of grit in their diet (e.g., Begg, 1954; Sengupta et al., 1999; Brook et al., 2006). Interproximal attrition reduces the space required for the teeth, and this translates into reduced arch length (e.g., Lysell, 1958; Fishman, 1973), though not as much as claimed by Begg ( $c f$. Murphy, 1964; Corruccini, 1999). Additionally, occlusal attrition reduces crown heights and, consequently, reduces lower face height
(Fishman, 1973). In turn, reduced crown heights allow the mandible to autorotate forward-and-upward, one consequence being that incisor overjet often is replaced by an edge-to-edge bite with horizontal wear on the incisal contacts (e.g., Begg, 1954). A related clinical issue is third molar impaction (Mucci 1982), like most occlusal variation a result simply of insufficient alveolar space for proper eruption, but this topic is usually treated differently because it is the province of a different clinical specialty, oral surgery as opposed to orthodontics.

In summary, this paper describes methods useful for quantifying the nature and extent of occlusal variation. Variations ("malocclusions") are very common in contemporary humans, but their origins, kinds, and geographic distributions are not well documented.

\section{REFERENCES CITED}

Angle EH. 1899. Classification of malocclusion. Dent Cosmos 41;248-264, 350-357.

Athanasiou AE. 1995. Orthodontic cephalometry. Baltimore: Mosby-Wolfe.

Barberia-Leache E, Suarez-Clúa MC, SaavedraOntiveros D. 2005. Ectopic eruption of the maxillary first permanent molar: characteristics and occurrence in growing children. Angle Orthod 75:610-615.

Baume LJ. 1950. Physiological tooth migration and its significance for the development of occlusion. II. The biogenesis of accessional dentition. J Dent Res 29:331-337.

Baume LJ, Horowitz HS, Summers CJ, Dirks OB, Brown WAB, Carlos JP, Cohen LK, Freer TJ, Harvold EP, Moorrees CFA, Salzmann JA, Schmuth G, Solow B, Taatz J. 1973. A method for measuring occlusal traits. Int Dent J 23:530-537.

Begg RP. 1954. Stone age man's dentition: with reference to anatomically correct occlusion, the etiology of malocclusion, and a technique for its treatment. Am J Orthod 40:298-312, 373-383, 462-475, 517-531.

Bernstein RL, Preston CB, Lampasso J. 2007. Leveling the curve of Spee with a continuous archwire technique: a long term cephalometric study. Am J Orthod Dentofacial Orthop 131:363-371.

Birkeland K, Boe OE, Wisth PJ. 2000. Relationship between occlusion and satisfaction with dental appearance in orthodontically treated and untreated groups. A longitudinal study. Eur J Orthod 22:509518.

Brace CL. 1977. Occlusion to the anthropological eye. In: McNamara JA, editor. The biology of occlusal development. Ann Arbor: Center for Human growth and Development. p 179-209.

Brook AH, Underhill C, Foo LK, Hector M. 2006. Approximal attrition and permanent tooth crown size in a Romano-British population. Dental 
Anthropology 19:23-28.

Brunelle JA, Bhat M, Lipton JA. 1996. Prevalence and distribution of selected occlusal characteristics in the US population, 1988-1991. J Dent Res 75:706713.

Cassidy KM, Harris EF, Tolley EA, Keim RG. 1988. Genetic influence on dental arch form in orthodontic patients. Angle Orthod 68:445-454.

Cerny R. 2005. What are the three most important reasons for orthodontic treatment? Are they aesthetics, aesthetics and aesthetics? Aust Orthod J 21:156-160.

Corruccini RS. 1987. Incisor overbite, overjet, and the $f$ hypothesis. Am Anthropol 89:947-948.

Corruccini RS. 1999. How anthropology informs the orthodontic diagnosis of malocclusions' causes. Lewiston, NY: Edwin Mellen Press.

Corruccini RS, Potter RHY. 1980. Genetic analysis of occlusal variation in twins. Am J Orthod 78:140154.

Davie S, Gray RMJ. 2001. What is occlusion? Br Dent J 191:235-238, 241-245.

DeKock WH. 1972. Dental arch depth and width studied longitudinally from 12 years of age to adulthood. Am J Orthod 62:56-66.

Ellis B. 1966. Basic concepts of measurement. London: Cambridge University Press.

Enoki K, Dahlberg AA. 1958. Rotated maxillary central incisors. Orthod J Japan 17:157-169.

Fanning EA. 1962. Effect of extraction of deciduous molars on the formation and eruption of their successors. Angle Orthod 32:44-53.

Fishman LS. 1976. Dental and skeletal relationships to attritional occlusion. Angle Orthod 46:51-63.

Grainger RM. 1967. Orthodontic treatment priority index. National Center for Health Statistics Series 2, no. 25. Washington, DC: Public Health Service.

Harris EF. 1997. A longitudinal study of arch size and form in untreated adults. Am J Orthod Dentofacial Orthop 111:419-427.

Harris EF. 2008. Interpreting heritability estimates in the orthodontic literature. Semin Orthod 14:125134.

Harris EF, Bodford K. 2007. Bilateral asymmetry in the tooth relationships of orthodontic patients. Angle Orthod 77:779-786.

HarrisEF, JohnsonMG.1991. Heritability of craniometric and occlusal variables: a longitudinal sib analysis. Am J Orthod Dentofacial Orthop 99:258-268.

Harris EF, Smith RJ. 1980. A study of occlusion and arch widths in families. Am Orthod 78:155-163.

Harris EF, Vaden JL, Williams RA. 1987. Lower incisor space analysis: A contrast of methodologies. Am J Orthod Dentofacial Orthop 92:375-380.

Harris JE. 1975. Genetic factors in the growth of the head: inheritance of the craniofacial complex and malocclusion. Dent Clin N Am 19:151-160.

Hillson S. 1996. Dental anthropology. Cambridge: Cambridge University Press.

Hillson S. 2005. Teeth, 2nd ed. Cambridge: Cambridge University Press.

Jenny J, Cons NC. 1996. Establishing malocclusion severity levels on the Dental Aesthetic Index (DAI) scale. Aust Dent J 1996;41:43-46.

Kao RT, Chu R, Curtis D. 2000. Occlusal considerations in determining treatment prognosis. J Calif Dent Assoc 28:760-769.

Kelly JE, Harvey CR. 1977. An assessment of the occlusion of youths 12-17 years. United States Public Health Service (Vital and Health Statistics, series 11, no. 162). DHEW Pub HRA 77-1644.

Klages U, Rost F, Wehrbein H, Zentner A. 2007. Perception of occlusion, psychological impact of dental esthetics, history of orthodontic treatment and their relation to oral health in naval recruits. Angle Orthod 77:675-680.

Knott VB. 1961. Size and form of the dental arches in children with good occlusion studied longitudinally from age 9 years to late adolescence. Am J Phys Anthropol 19:263-284.

Knott VB. 1972. Longitudinal study of dental arch widths at four stages of dentition. Angle Orthod 42:387-394.

Little RM. 1975. The irregularity index: a quantitative score of mandibular anterior alignment. Am J Orthod 68:554-563.

Lombardi AV, Bailit HL. 1972. Malocclusion in the Kwaio, a Melanesian group on Malaita, Solomon Islands. Am J Phys Anthropol 36:283-294.

Lysell L. 1958. A biometric study of occlusion and dental arches in a series of medieval skulls from northern Sweden. Acta Odont Scand 16:177-203.

Mills LF.1964. Epidemiological studies of malalignment. I. A study of arch width, arch length, and tooth size. Angle Orthod 34:124-129.

Mohlin B, Kurol J. 2003. To what extent do deviations from an ideal occlusion constitute a health risk? Swed Dent J 27:1-10.

Moorrees CFA. 1959. The dentition of the growing child. Cambridge: Harvard University Press.

Moorrees CFA, Reed RR. 1954. Biometrics of crowding and spacing of the teeth in the mandible. Am J Phys Anthropol 12:77-88.

Morrey LW, Nelsen RJ. 1972. Dental science handbook. U.S. Public Health Service. DHEW Pub NIH 72336.

Moyers RE. Handbook of orthodontics, 4th ed. Chicago: Year Book Medical Publishers, Inc., 1988.

Mucci RJ. 1982. The role of attrition in the etiology of third molar impactions: confirming the Begg hypothesis. Thesis, University of Illinois at Chicago Circle. 
Murphy TR. Reduction of the dental arch by approximal attrition. Br Dent J 116:483-488.

Nakata M, Yu P-L, Davis B, Nance WE. 1974a. Genetic determinants of cranio-facial morphology: a twin study. Ann Hum Genet 37:431-442.

Nakata M, Yu P-L, 1974b. Nance WE. 1974b. Multivariate analysis of cranio-facial measurements in twin and family data. Am J Phys Anthropol 41:423-430.

National Center for Health Statistics. 1994. Plan and operation of the Third National Health and Nutrition Examination Survey, 1988-94. Washington, DC: Vital Health Statistics, Series 1, No. 32.

Owens S, Buschang PH, Throckmorton GS, Palmer L, English J. 2002. Masticatory performance and areas of occlusal contact and near contact in subjects with normal occlusion and malocclusion. Am J Orthod Dentofacial Orthop 121:602-609.

Picton DC, Moss JP. 1973. The part played by the transseptal fibre system in experimental approximal drift of the cheek teeth of monkeys (Macaca irus). Arch Oral Biol 18:669-680.

Proffit WR. 1985. On the aetiology of malocclusion. The Northcroft lecture, 1985 presented to the British Society for the Study of Orthodontics, Oxford, April 18, 1985. Br J Orthod 13:1-11.

Proffit WR. Contemporary orthodontics, 4th ed. St Louis: Mosby, 2007.

Ramfjord, Ash MM. 1971. Occlusion, 2nd ed. Philadelphia: WB Saunders Company.

Sengupta A, Whittaker DK, Barber G, Rogers J, Musgrave JH. 1999. The effects of dental wear on third molar eruption and on the curve of Spee in human archaeological dentitions. Arch Oral Biol 44:925-934.

Serio FG, Hawley CE. 1999. Periodontal trauma and mobility. Diagnosis and treatment planning. Dent Clin North Am 43:37-44.

Shaw WC. 1981. The influence of children's dentofacial appearance on their social attractiveness as judged by peers and lay persons. Am J Orthod 79:399-415.

Shaw WC, Gabe MJ, Jones BM. 1979. The expectations of orthodontic patients in South Wales and St. Louis, Missouri. Br J Orthod 6:203-205.
Shaw WC, Rees G, Dawe M, Charles CR. 1985. The influence of dentofacial appearance on the social attractiveness of young adults. Am J Orthod 87:2126.

Siegel MA. 2002. A matter of Class: interpreting subdivision in a malocclusion. Am J Orthod Dentofacial Orthop 122:582-586.

Sillman JH. 1964. Dimensional changes of the dental arches: longitudinal study from birth to 25 years. Am J Orthod 50:824-842.

Smith BH. 1984. Patterns of molar wear in hungergatherers and agriculturalists. Am J Phys Anthropol 63:39-56.

Smith RJ, Bailit HL. 1977. Variation in dental occlusion and arches among Melanesians of Bougainville Island, Papua New Guinea. I. Methods, age changes, sex differences and population comparisons. Am J Phys Anthropol 47:195-208.

Southard TE, Behrents RG, Tolley EA. 1989. The anterior component of force. Part 2. relationship with dental malalignment. Am J Orthod Dentofacial Orthop 97:41-44.

Tompkins RL. 1996. Human population variability in relative dental development. Am J Phys Anthropol 99:79-102.

Traebert ES, Peres MA. 2007. Do malocclusions affect the individual's oral health-related quality of life? Oral Health Prev Dent 5:3-12.

Turner RA. 2007. Quantitative analysis of first- versus second-premolar extraction effects in orthodontic treatment. M.D.S. Thesis, University of Tennessee, Memphis.

Van Norman RA. 1997. Digit-sucking: a review of the literature, clinical observations and treatment recommendations. Int J Orofacial Myology 23:14-34.

Van Vark LE Jr, Pennell EH. 1959. Assessment of malocclusion in population groups. Am J Orthod 45:752-758.

Wheeler RC. 1965. A textbook of dental anatomy and physiology, 4th ed. Philadelphia: WB Saunders Company. 